\title{
Brexit and Its Impact on Pharmaceutical Law: Implications for Global Pharma Companies
}

\author{
Johannes Heusler
}

\begin{abstract}
With the United Kingdom's (UK) referendum on the 23rd of June 2016 the majority of the British electorate voted for a withdrawal of the UK from the European Union. The term Brexit was already established some time before, but now it became reality. Based on the outcome of the referendum, on 29th of March 2017 Prime Minister Theresa May officially handed in the application for the exit according to Article 50 of the Treaty on the European Union. As a consequence, the UK will have to leave the European Union until the 29th of March 2019.
\end{abstract}

After the momentous referendum vote and connected withdrawal decision, a lot of discussion about the economic, legal and social outcomes of the first in history withdrawal of an EU member state arose. There are still many uncertainties on how the exit will look like and what the consequences are. Brexit and also its potential implications for the regulatory environment within the health care system quickly became one of the hot topics within the pharmaceutical industry. Due to the highly regulated environment surrounding medicinal products throughout their life cycle, the favours of the Union have become more vital than in any other sector of industry.

The derogation coming along with the UK's withdrawal are therefore expected by many to hit pharma exceedingly hard. Especially multinational pharmaceutical companies operating in the UK might be affected in various ways and areas and therefore need to prepare for changes by identifying key business issues, mitigating risks and creating plans for multiple scenarios.

The future development as well as the post-Brexit relationship between the UK and the EU are hard to predict. As negotiations are ongoing some tendencies on how the future relationship could look like became apparent. However, there are still many open questions for the industry as well as for the regulators. This might lead to serious risks but maybe also opportunities connected with the different Brexit scenarios and their impact on pharmaceutical law.

\footnotetext{
J. Heusler $(\bowtie)$

Roche Pharma AG, Grenzach-Wyhlen, Germany

e-mail: johannes.heusler@roche.com
} 
This master thesis provides a comprehensive evaluation of potential changes to the regulatory framework and their consequences, while focusing on the following key areas:

- Marketing authorisations and drug approval procedures

- Drug manufacturing: rules on Good Manufacturing Practice (GMP) and quality of pharmaceutical products

- Pharmacovigilance

- Clinical trials

The evaluation finally aims for providing guidance for global pharma companies, which are facing challenges in that specific area. What are the potential impacts and risks that are connected with different Brexit scenarios and the related changes to the regulatory environment for pharmaceuticals? Which aspects do impacted companies need to consider in order to prepare for different Brexit scenarios?

To answer those questions, the master thesis is focusing on review and discussion of currently available publications and literature in this field and evaluate different options and scenarios. The scenarios are assessed regarding their impact on the pharmaceutical industry, while summarizing potential risks and possible mitigation actions. The review also takes into consideration expert opinions from regulators and industry associations. The master thesis is supposed to scrutinize the currently available information and summarize the potential impact on the regulatory environment. This is the basis to derive guidance for companies to prepare for the different scenarios, taking into account their respective probability of occurrence. Impact on health authorities, e.g. the European Medicines Agency (EMA), and consequences for health care systems related to the discussed aspects are also taken into consideration. Own ideas for problem solutions are introduced as applicable.

The master thesis is reflecting the state of affairs as of the 7th of August 2018.

Due to procedural reasons any publication or event after this date is not considered anymore. The following chapters represent a compendious aggregation of the master thesis content but not the full text of the original master thesis.

\section{Brexit Scenarios}

The UK's withdrawal from the European Union is supposed to be set in stone since Prime Minister Theresa May officially handed in the respective invocation according to Article 50 of the Treaty on European Union on 29th of March 2017. According to the given procedure for leaving the EU the period for related negotiations is limited to two years. Unless there will be an agreed extension, the EU treaties will cease to apply on 29th of March 2019 at midnight. The statutory negotiations technically started when the UK submitted the notification letter. This chapter provides an overview on the guidelines for the Brexit negotiations as agreed by the group representing the remaining EU27 member states in the EU Council late April 2017. Furthermore, the possibility of a transitional period as well as four basic exit scenarios resulting in different types of post-Brexit relationship between the EU and 
the UK are assessed: The EEA scenario, the EFTA scenario, the FTA scenario and the WTO scenario.

The WTO no-deal scenario is expected to have the maximum impact on the pharma industry with total separation of the UK systems for pharmaceutical regulation from the EU. According to the overall assessment, a hard Brexit seems to be the most likely scenario considering the current state of affairs, but there is still hope that at least some kind of free trade and mutual recognition agreement will be negotiated. Considering the limited time until the withdrawal becomes effective, the political disagreement that is still predominant in the UK as well as the sagging negotiations between both parties, the risk that the UK will leave the EU without a deal must not be underestimated.

\section{Impact on the Drug Regulatory Framework}

This chapter addresses the potential impact of the UK's withdrawal from the European Union on the European drug regulatory framework. Still, there are many uncertainties connected with the UK's withdrawal from the European Union and the resulting non-applicability of European pharmaceutical legislation. Following the progress of ongoing discussions and negotiations it seems to be rather unlikely that the EU will seek any EEA or EFTA membership. Instead the future relationship seems to be strongly dependent on how successful the negotiators will be in swiftly reaching a consensus on a bilateral contractual framework outlining the terms and conditions of the future relationship, including agreements on free movement of medicines and mutual recognition of related regulation and procedures. At this stage the impact on pharmaceutical law is accordingly undetermined and may vary significantly depending on the possible mutual recognition of drug regulatory key issues.

After considering the general drug regulatory environment selected the following key aspects are discussed in the respective sub-chapters: Relocation of the EMA, Marketing authorisations, drug manufacturing, pharmacovigilance and clinical trials.

\section{Recommended Actions for Companies}

Unfortunately, the most probable post-Brexit scenario seems to be that the UK will become a third country after leaving the EU, entailing significant changes of the drug regulatory environment. Even if there is hope that agreements of mutual recognition will be put in place subsequently, the industry needs to prepare for the regulatory consequences related to the 'no deal third country situation', which is about to become reality end of March 2019. Relying on the transitional period or betimes available arrangements is considered highly risky. 
In a summary report that was published by the European Commission in March 2018 following a technical seminar addressing questions related to pharmaceuticals, the authority clearly expressed concerns regarding the level of preparedness of the industry (Boehm 2018). In the meantime, the situation may have changed as most likely more and more companies have become aware of the seriousness of the situation. However, it is assumed that there is still need for action in the industry, justifying the elaboration of recommendations for companies as outlined below.

Pharmaceutical companies play a critical role in ensuring continued supply of medicines after Brexit and in minimizing expected disruptions and impact on public health in the UK and the EU.

The first step to prepare for Brexit is to identify and analyse the company specific key business issues and areas requiring adaptions. This is prerequisite for creating mitigation strategies and concrete action plans. The consequences can be quite serious. In the worst case the companies might even be forced to revoke products from the market. The sooner the companies start acting the lower is the risk of running into Brexit-related regulatory non-compliances or supply issues.

The list of questions that should be carefully assessed by the companies is quite long, including the following examples: Which organizational changes are necessary? Which processes need to be adapted? Which products and supply chains are affected? Which transfers of pharmacovigilance, manufacturing, testing or release activities are needed and what are the different options?

Pharmaceutical companies that seek market access of their products in the UK and in the EU member states in the future must have at least a legal entity in both territories representing the marketing authorisation holder for each product. This is primarily impacting companies that used to have their centralised marketing authorisations based in the UK. Without transferring the marketing authorization holder to one of the remaining EU/EEA member states, such products may not anymore be released to the EU/EEA market after exit day. Of course such changes usually are associated with additional financial and human resources. Detailed planning of such transfers and related timelines in alignment with other ongoing regulatory activities related to the concerned products is indispensable, especially if there are numerous licences concerned. Companies should act as soon as possible in order to make sure the required resources are available in due time, supporting a smooth transition and transfer of activities.

Related artworks changes, usually affecting folding boxes and patient information leaflets, should be initiated in due time to ensure undisrupted supply of regulatory compliant medicinal products after the MHA transfer.

Pending requests for transfers of RMS responsibility to an EU/EEA member state should be initiated immediately. It is essential to assess the suitability of the new RMS country. For example, all available formulations and strengths of the products must be registered in the proposed EU/EEA member state. The transfer of RMS responsibility must be agreed by both MHRA and the competent authority of the to-be RMS.

Companies that used to have legal representatives for clinical trials in the UK need to assess the need for transfers of this role to an EU/EEA member state. 
Depending on the number of trials requiring such changes the transfer of the legal entity could trigger a substantial amendment for all multinational or global clinical trials with any EU/EEA country participating in countries where a grouped amendment for all studies will not be possible. Similar to the transfer of licenses, a detailed plan and timetable would be necessary to integrate the change into other substantial amendments or initial clinical trials to reduce the resource burden.

Acquisition of key personnel such as the QP or the QPPV might also represent a challenge for companies that need to transfer those roles and related activities from the UK to a site in the EU/EEA. Therefore, companies should not wait too long to start recruiting or staff relocation activities. In addition, there might also be opportunities for internal talent management and selective personnel development in order to fill such positions.

Transfers of regulatory relevant activities, such as importation, QP certification, release testing or storage of reference samples is usually connected with high efforts and costs regarding sourcing and qualification. In the best case the company has already labs or release/importation organisations in place in the EU/EEA that can act as acceptor site for such activities. Especially if a new location needs to be established, the investment and expenditure of time usually is incomparably higher. Outsourcing of selected activities to contractors could be an option.

Due to expected bottlenecks regarding the processing of regulatory relevant changes by the authorities, respective preparation and submission of marketing authorization holder transfers and variations should be made sufficiently early. Any last-minute action should be avoided.

It is strongly advised to proactively get in touch with relevant authorities, e.g. EMA and seek support and advice, especially in case of open questions regarding the changing regulatory environment.

Building up safety stocks of material that was already released to saleable stock could help to bypass a certain period of pending approvals and safeguard companies against running into supply issues. Some of the major pharmaceutical companies such as Novartis and AstraZeneca already informed the public about plans to increase their stockpiles for that reason (Mancini 2018) and (Sabbagh 2018). Indeed, this seems to be a good backup, at least for companies that are not sure if they will manage to have all necessary transfers and approvals in place allowing for regular and compliant release of their products post-Brexit.

Companies operating in the EU and the UK are usually impacted in several ways and the challenges they are facing mostly prove to be rather complex. It is therefore recommended to establish a cross-functional Brexit Working Group within the company including drug regulatory subject matter experts as well as representatives from the impacted sites and departments such as manufacturing, quality, artwork management, drug safety, clinical development and legal. Supportive functions like informatics or human resources (e.g. when it comes to recruiting of relevant key personnel) might be involved as needed. Depending on the identified key issues, management should clearly define the respective roles and responsibilities of this taskforce. In addition, it is essential to establish reporting structures, escalation pathways and business processes facilitating a functioning co-operation of executing 
departments regarding the timely implementation of agreed actions. Close collaboration between all involved sites and functions is indispensable. For example, the Brexit Working Group could perform the following tasks:

- Initiate and track necessary actions according to a detailed action plan that is based on the ongoing impact assessment. Regular reviews and reassessments are obligatory due to the many uncertainties regarding the political development and potentially changing regulatory implications as Brexit negotiations are running. At this point a lot of information is still pending.

- Provide support for the transfers and redistribution of activities and staff relocation as applicable.

- Coordinate marketing authorisation transfers, orphan drug designation transfers and variations regarding manufacturing, import testing as well as release activities and drive respective dossier preparation.

- Ensure close collaboration with relevant health authorities, e.g. EMA and MHRA, meaning that the Brexit Working Group is accountable for the overall plans and at the same time remains in close exchange with the appropriate contact persons at the authorities. If possible, the working group should be the single point of contact for any Brexit-related communication with authorities. At a minimum any such health authority communication should be aligned with the working group as a coordinating function.

- Keep stakeholders informed and escalate issues to upper management as needed.

- Increase internal awareness about the expected changes of the pharma regulatory framework and the resulting need for adaptation. This could be done by internal newsletters, trainings or informative talks at town hall meetings.

- Exchange with relevant industry associations and, as applicable, with other companies facing similar challenges.

This list of suggested activities is to be considered as a general recommendation and needs to be adapted to the specific needs of the company.

Another recommendation is to engage actively in lobbying. Companies should use their policy departments or other appropriate functions to constantly address any pain points or risks the company is facing related to Brexit and the upcoming changes of the drug regulatory framework. Collaboration with other affected companies and membership in industry associations has proven to be an effective way to make sure that the voice of the industry will not be missed in ongoing negotiations and political discussions. Many companies have been actively involved in forming the voice of the industry ever since the UK's withdrawal referendum, mainly through industry associations such as EFPIA, B.A.H. or vfa, in order to influence the political trends. However, for companies that used to be rather reserved and did not yet utilize their full potential in this field it is still not too late to start taking an active role and engage in shaping the industry's future. 


\section{Conclusions and Outlook}

Brexit is surely amongst the biggest challenges for the pharma industry in the present age. In order to make estimations on the implications and recommendations for companies, careful evaluation of the political situation and regulatory framework is essential. In the first part of the master thesis three basic scenarios have been discussed related to the post-Brexit relationship between the EU and the UK: the EEA scenario, the EFTA scenario and the WTO/FTA scenario. The latter one is clearly considered to be the most likely basic scenario. However, the overall impact strongly varies between the sub scenarios which are subject to different kinds of free trade agreement options. The so-called 'hard' Brexit seems to be the most likely scenario considering the current state of affairs and the risk of a no-deal scenario is growing constantly as the exit date is coming closer. Most likely there will be a transition agreement covering the period from exit day until end of December 2020. However, considering the plenty of open problems to be solved and questions to be clarified, the risk remains high that the new exit date of new year's eve 2020 might still not be sufficient in order to ensure an orderly exit and to settle adequate agreements regarding the future relationship between the UK and the EU.

Some hope is still left that there might be some kind of free trade agreement in place at the day of Brexit paving the way for contractual arrangements of mutual recognition related to major drug regulatory aspects between the UK and the EU. However, the probability of occurrence for a no-deal hard Brexit seems to be dominating. Consequently, this is the scenario that the industry is recommended to prepare for, especially in order to mitigate risks for patients and public health.

The comprehensive evaluations of selected key areas of pharmaceutical law revealed that such a no-deal Brexit would severely impact multinational pharmaceutical companies operating in the UK. Such companies are usually affected in various ways and need to prepare accordingly.

Installing a Brexit Working Group or taskforce assessing the need for action and coordinating the resulting activities is considered to be a kind of best practice approach, at least for companies that need to deal with several adaptions and changes in parallel. Taking action proactively and sufficiently early is key in order to ensure adequate preparedness and to minimize any risk for non-compliances and resulting supply issues of pharmaceutical products.

At this stage of negotiations there are still many uncertainties. The different scenarios and their evaluation may be useful to understand the potential consequences and to prepare as good as possible for the expected changes of the regulatory framework. Yet, only the future will show the final impact of Brexit on the industry and public health. Without any doubt Brexit will serve as a gigantic case study. It would be interesting to review the evaluations and recommendations of this master thesis in some years and compare it to the actual events as part of the such a case study. 


\section{References}

Boehm, J. (2018). Summary record technical expert seminar on pharmaceuticals related matters, following UK withdrawal.

Mancini, D. P. (2018). Novartis plant Arzneimittelvorräte für ungeordneten Brexit. Retrieved from Dow Jones Newswire Web website: http://www.finanztreff.de/news/novartis-plantarzneimittelvorraete-fuer-ungeordneten-brexit/13436483

Sabbagh, D. (2018). EU patients may miss out on medicines in no-deal Brexit, says AstraZeneca. Retrieved from The Guardian website: https://www.theguardian.com/politics/2018/aug/07/eupatients-may-miss-out-on-medicines-in-no-deal-brexit-says-astrazeneca

Open Access This chapter is licensed under the terms of the Creative Commons Attribution 4.0 International License (http://creativecommons.org/licenses/by/4.0/), which permits use, sharing, adaptation, distribution and reproduction in any medium or format, as long as you give appropriate credit to the original author(s) and the source, provide a link to the Creative Commons licence and indicate if changes were made.

The images or other third party material in this chapter are included in the chapter's Creative Commons licence, unless indicated otherwise in a credit line to the material. If material is not included in the chapter's Creative Commons licence and your intended use is not permitted by statutory regulation or exceeds the permitted use, you will need to obtain permission directly from the copyright holder.

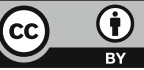

